\title{
Chapter 4 \\ Coseismic Tsunami Simulation Assuming the Displacement of High-Angle Branching Active Faults Identified on the Continental Slope Around the Japan Trench
}

\author{
Shota Muroi and Takashi Kumamoto
}

\begin{abstract}
The aim of this study is to demonstrate the tsunami potential caused by high-angle branching faults with relatively low net slip compared to that of the 2011 off the Pacific coast of Tohoku (Tohoku-oki) earthquake of Mw9.0, located in the upper part of the mega-thrust along the Japan Trench where the Tohoku-oki earthquake ruptured, as deduced from the distribution of active faults illustrated by a bathymetric geomorphological study and seismic profile records (Nakata et al. Active faults along Japan Trench and source faults of large earthquakes. http://www.jaee.gr.jp/event/seminar2012/eqsympo/pdf/papers/34.pdf. 19 Dec 2012). The results show that the expected tsunami from high-angle branching faults becomes about one and a half times as high as the case of low-angle thrust faults. This demonstrates the importance of the distribution of high-angle branching faults on the continental slope and their subsurface structure in tsunami hazard assessment.
\end{abstract}

Keywords Japan Trench • High-angle branching faults • Tsunami potential

\subsection{Introduction}

The recent development of a detailed digital bathymetry dataset in Japan enables the interpretation of offshore tectonic landforms and the identification of the distribution of active faults, especially around plate boundaries, such as the Japan Trench and the Nankai Trough. For example, Nakata et al. [1] reported several newly identified tectonic landforms and active faults on the continental slope situated parallel to the axis of the Japan Trench where the 2011 off the Pacific

\footnotetext{
S. Muroi

Kokusai Kogyo CO., LTD, Nishinagasumachi 1-1-15, Amagasaki 660-0805, Japan

T. Kumamoto $(\bowtie)$

Faculty of Science, Okayama University, Tsushimanaka 3-1-1, Kita-ku, Okayama 700-8530,

Japan

e-mail: tkuma@cc.okayama-u.ac.jp
} 


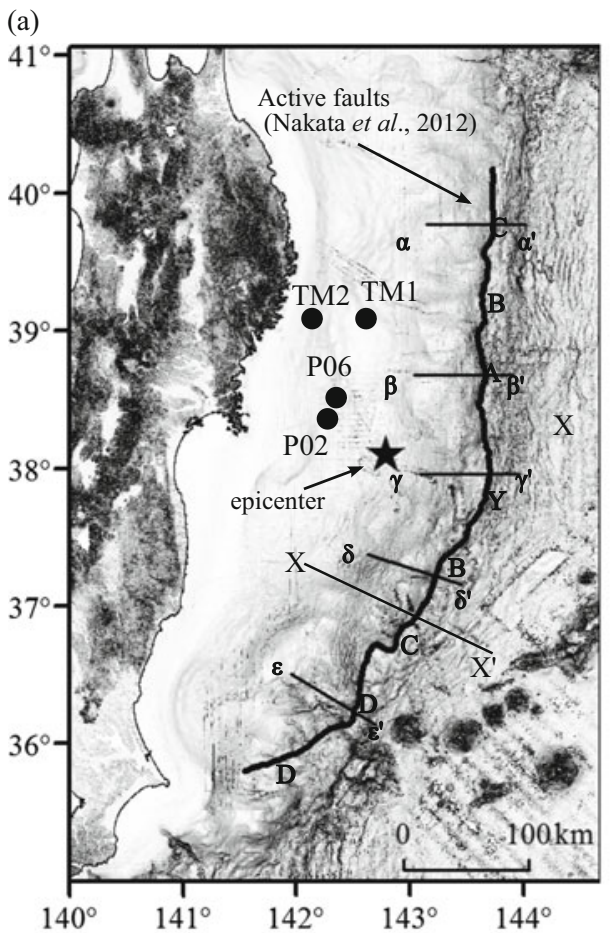

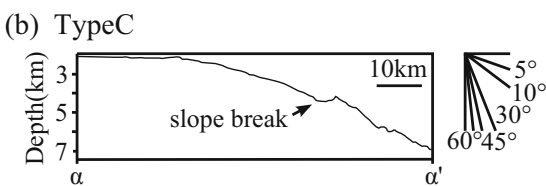

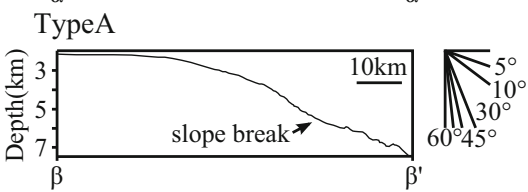

TypeY

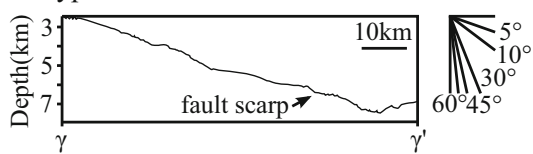

TypeB
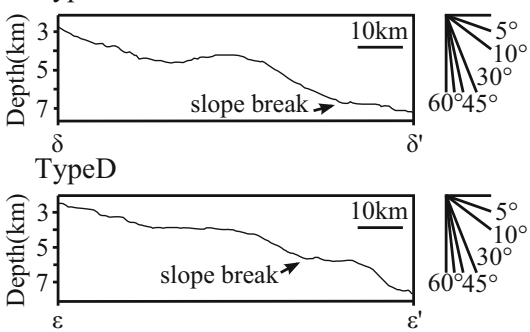

(c)
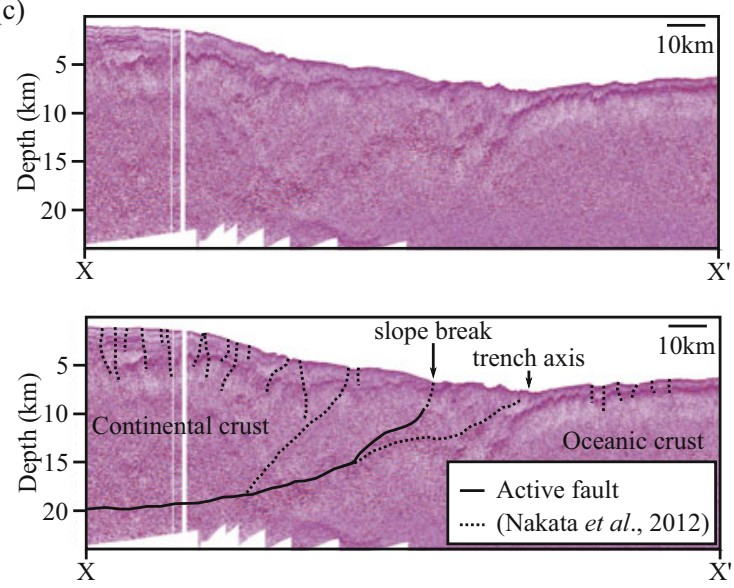

Fig. 4.1 Tectonic landforms identified off the coast of Tohoku. (a) The submarine active fault distributions of Nakata et al. (2012), (b) typical tectonic landform profiles of the sections in (a), (c) multichannel seismic profile record (top, Kato [3]; bottom, our interpretation) 
coast of Tohoku (Tohoku-oki) Earthquake of Mw9.0 ruptured, by using 3D-anaglyph figures derived from a 150-m resolution Digital Bathymetry Model.

The present study demonstrates (a) the tsunami potential produced by a future earthquake due to active faults on the continental slope identified in the fault distribution map of Nakata et al. [1] (Fig. 4.1a, hereafter, Nakata map) and (b) the influence of high-angle branching faults. Although there is a lack of consensus regarding the type of tectonic landforms and active faults on the continental slope along the Japan Trench from the interpretation of seismic profile records (e.g., Okamura [2]), we discuss the tsunami potential based on the Nakata map produced from geomorphological studies because the existing planar subsurface structural dataset is still insufficient to provide an unequivocal representation of these continental slope features.

\subsection{Active Fault Distribution}

The earthquake source fault model in this study is constructed from the active faults on the continental slope along the Japan Trench displayed in the Nakata map with a total length of more than $400 \mathrm{~km}$. These active faults can be roughly divided into the following two groups: The first group consists of faults situated at the base of the continental slope along the axis of the Japan Trench offshore between Kuji, Iwate Prefecture $\left(40^{\circ} \mathrm{N}\right)$ and Mito, Ibaraki Prefecture $\left(36^{\circ} \mathrm{N}\right)$ displaying a relatively linear form along their strike with fresh scarps indicating recent activity (Fig. 4.1b, sections of type Y). The second group consists of faults situated on the continental slope continuing outward on both sides of the first group faults that display a relatively sinuous form with slope breakpoints (Fig. $4.1 \mathrm{~b}$, sections of type A, $\mathrm{B}, \mathrm{C}$, and D).

The second group active faults in the Nakata map can be recognized in the seismic profiling record of Kato [3]. The upper figure of Fig. 4.1c shows an example of a seismic profile record along the $X-X^{\prime}$ traverse line in Fig. 4.1a, and the lower figure of Fig. 4.1c shows our interpretation of type $\mathrm{C}$ high-angle branching faults with surface slope break on the continental slope. In this seismic profile record, the type $\mathrm{C}$ fault branches from the decollement plane between the continental and oceanic crusts with a relatively high angle of $25-28^{\circ}$ compared to the low-angle decollement plane of approximately $14^{\circ}$. Ueta and Tani [4] performed an experimental simulation of thrust fault development and demonstrated the deformation process of strata with the creation of high-angle branching faults from low-angle thrust. Thus, the combination of low-angle decollement plane with high-angle branching faults is a universal phenomenon, and it is important to assess the earthquake and tsunami potential of the high-angle branching faults around a subduction zone in addition to that of plate-boundary-type earthquakes.

According to the Nakata map, the height of the tectonic scarp along the highangle branching faults varies from 2 to $3 \mathrm{~km}$ along the strike. We considered that the height difference of the tectonic scarp corresponds to the difference in 
cumulative displacement of previous repeating earthquakes and therefore is related to both the coseismic displacement and relative activity of the faults. From a viewpoint of interpretation of tectonic landforms, it is characterized that type $\mathrm{Y}$ section shows the highest tectonic scarp in the Nakata map, and types A to D sections show the difference of tectonic scarp height in descending order.

\subsection{Fault Parameters}

The parameters of location, length, strike, dip angle, depth of fault upper edge, and fault width for the earthquake source fault model were determined using the fault distribution and character of the tectonic scarps in the Nakata map. First, the location, length, and strike were determined from the type differences in the Nakata map from ten linear sections with different lengths between 30 and $80 \mathrm{~km}$ and the individual strike (Fig. 4.2a) Second, the dip angle and the depth of the fault upper edge were examined by comparing the Nakata map with the seismic profile records (e.g., Kato [3]; Fig. 4.1c). The dip angle of type Y section in the Nakata map corresponds to the decollement of the plate boundary, and the average of $14^{\circ} \mathrm{W}$ was assigned to the parameters from several seismic profile records ranging from $12^{\circ} \mathrm{W}$ to $16^{\circ} \mathrm{W}$. The depth of the fault upper edge was assigned as $0 \mathrm{~km}$ since the decollement of the plate boundary reaches the sea bottom.

The dip angles of types A to D sections of high-angle branching faults were assigned as $26^{\circ} \mathrm{W}$ from several seismic profile records ranging from $25^{\circ} \mathrm{W}$ to $28^{\circ} \mathrm{W}$. The tectonic landforms of these sections display a humped form with a relatively long wavelength of $20 \mathrm{~km}$, and such hump-shaped tectonic landforms have been observed empirically when the upper fault edge was buried beneath the subsurface. Thus, the depth of the fault upper edges of these types was $5 \mathrm{~km}$ beneath the tectonic scarps on the sea bottom, as shown in Fig. 4.1c. For the fault width, the parameters of low-angle decollement plane (e.g., Fujii and Satake [5], Fig. 4.2a) for the 2011 Tohoku-oki earthquake were referred since the high-angle branching faults in this study converged to the decollement of the plate boundary (Fig. 4.1c).

Subsequently, the average slip value of $11 \mathrm{~m}$ was calculated from the empirical equation of fault area and average displacement given in "A Formula for the Prediction of Strong Ground Motion of Subduction-Type Earthquakes" [6]. Finally, the slip distribution of 25 sub-faults was assigned using a trial-and-error method under the following four constraint conditions: (1) the total seismic moment is preserved, (2) the maximum slip is almost twice the average slip according to the formula of HERP [6], (3) the area of maximum slip is almost $20 \%$ of the total fault area according to the formula of HERP [6], and (4) the slip distribution of the section of decollement is close to that of the 2011 Tohoku-oki earthquake since our model shared the deep part of the low-angle fault plane with that of the 2011 Tohoku-oki earthquake as the decollement of the plate boundary.

The resulting model parameters (Model1) are summarized in Table 4.1 and Fig. 4.2b. The amount of slip and the area of the asperity of the formula [6] were 
(a)

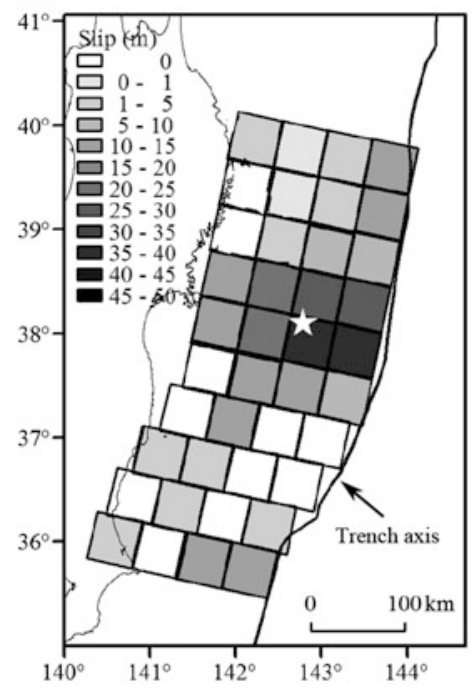

(c)

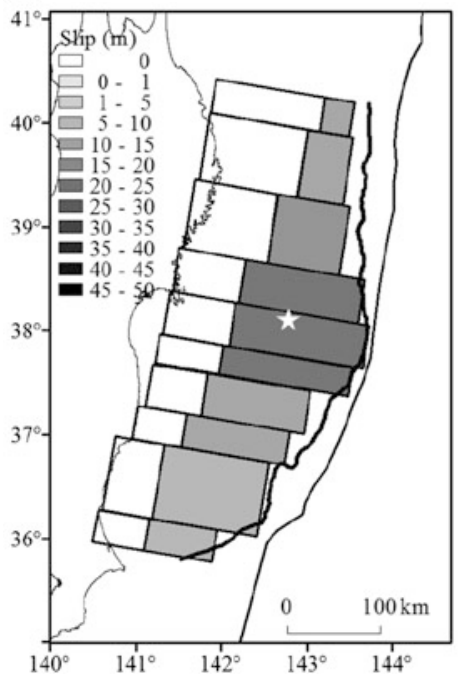

(b)

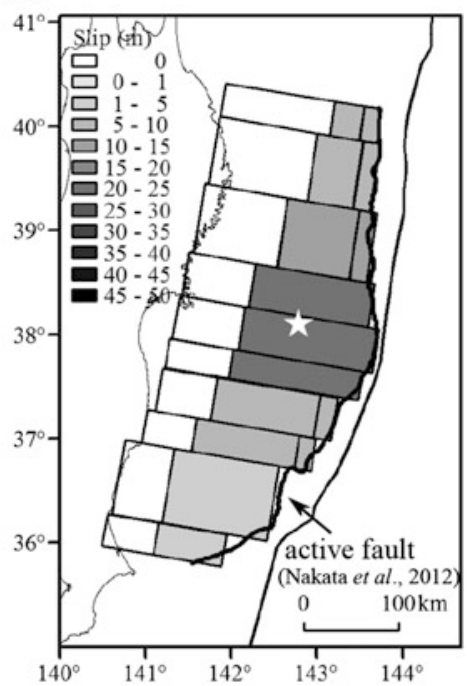

(d)

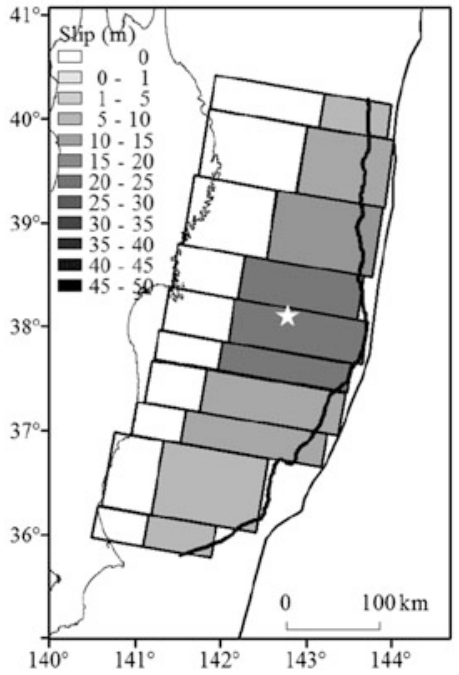

Fig. 4.2 Earthquake source fault models. (a) The 2011 Tohoku-oki earthquake from Fujii and Satake [5]; (b) Model1, the high-angle branching fault model of this study; (c) Model2, sub-faults of Model1 without high-angle branching part; (d) Model3, sub-faults of Model2 and extended sub-faults to the sea bottom with same low-angle and same slip amount. The epicenter of the 2011 Tohoku-oki earthquake is indicated by an asterisk

in close agreement with those of the shallow part of the sub-faults along the type $\mathrm{Y}$ section in the Nakata map. It is important to note that the location and depth of the upper fault edge of the type A to D sections as high-angle branching faults in 
Table 4.1 Fault parameters used in the earthquake source fault model (Fig. 4.2b-d)

\begin{tabular}{l|l|l|l|l|l|l|l|c|c}
\hline ID & $\begin{array}{l}\text { Latitude } \\
(\mathrm{deg})\end{array}$ & $\begin{array}{l}\text { Longitude } \\
(\mathrm{deg})\end{array}$ & $\begin{array}{l}\text { Depth } \\
(\mathrm{km})\end{array}$ & $\begin{array}{l}\text { Strike } \\
(\mathrm{deg})\end{array}$ & $\begin{array}{l}\text { Dip } \\
(\mathrm{deg})\end{array}$ & $\begin{array}{l}\text { Rake } \\
(\mathrm{deg})\end{array}$ & $\begin{array}{l}\text { Length } \\
(\mathrm{km})\end{array}$ & $\begin{array}{l}\text { Width } \\
(\mathrm{km})\end{array}$ & $\begin{array}{l}\text { Slip } \\
(\mathrm{m})\end{array}$ \\
\hline 1 & 40.1 & 144.0 & 5 & 190 & 27 & 90 & 36 & 20 & 6 \\
\hline 2 & 40.2 & 143.7 & 15 & 190 & 14 & 90 & 36 & 32 & 6 \\
\hline 3 & 40.2 & 143.4 & 23 & 190 & 14 & 90 & 36 & 121 & 0 \\
\hline 4 & 39.8 & 143.9 & 5 & 190 & 27 & 90 & 71 & 20 & 10 \\
\hline 5 & 39.8 & 143.7 & 15 & 190 & 14 & 90 & 71 & 49 & 10 \\
\hline 6 & 39.9 & 143.1 & 27 & 190 & 14 & 90 & 71 & 109 & 0 \\
\hline 7 & 39.1 & 143.9 & 5 & 190 & 27 & 90 & 73 & 20 & 14 \\
\hline 8 & 39.2 & 143.6 & 15 & 190 & 14 & 90 & 73 & 78 & 14 \\
\hline 9 & 39.3 & 142.8 & 34 & 190 & 14 & 90 & 73 & 92 & 0 \\
\hline 10 & 38.5 & 143.8 & 0 & 190 & 14 & 90 & 46 & 129 & 21 \\
\hline 11 & 38.7 & 142.3 & 31 & 190 & 14 & 90 & 46 & 74 & 0 \\
\hline 12 & 38.0 & 143.8 & 0 & 190 & 14 & 90 & 46 & 145 & 21 \\
\hline 13 & 38.3 & 142.2 & 35 & 190 & 14 & 90 & 46 & 73 & 0 \\
\hline 14 & 37.6 & 143.6 & 0 & 190 & 14 & 90 & 30 & 140 & 21 \\
\hline 15 & 37.9 & 142.1 & 34 & 190 & 14 & 90 & 30 & 70 & 0 \\
\hline 16 & 37.4 & 143.3 & 5 & 190 & 27 & 90 & 45 & 20 & 10 \\
\hline 17 & 37.4 & 143.1 & 15 & 190 & 14 & 90 & 45 & 111 & 10 \\
\hline 18 & 37.6 & 141.9 & 42 & 190 & 14 & 90 & 45 & 61 & 0 \\
\hline 19 & 37.0 & 143.0 & 5 & 190 & 27 & 90 & 35 & 20 & 6 \\
\hline 20 & 37.0 & 142.8 & 15 & 190 & 14 & 90 & 35 & 111 & 6 \\
\hline 21 & 37.2 & 141.6 & 42 & 190 & 14 & 90 & 35 & 54 & 0 \\
\hline 22 & 36.7 & 142.6 & 0 & 190 & 14 & 90 & 78 & 113 & 5 \\
\hline 23 & 36.9 & 141.3 & 27 & 190 & 14 & 90 & 78 & 55 & 0 \\
\hline 24 & 36.1 & 142.0 & 0 & 190 & 14 & 90 & 34 & 74 & 5 \\
\hline 25 & 36.2 & 141.2 & 18 & 190 & 14 & 90 & 34 & 56 & 0 \\
\hline $\mathrm{a}$ & 40.10 & 144.21 & 0.10 & 190 & 14.0 & 90 & 36 & 75 & 4 \\
\hline $\mathrm{b}$ & 39.75 & 144.22 & 0.10 & 190 & 14.0 & 90 & 71 & 96 & 7 \\
\hline $\mathrm{c}$ & 39.11 & 144.05 & 0.10 & 190 & 14.0 & 90 & 73 & 117 & 12 \\
\hline $\mathrm{d}$ & 37.34 & 143.54 & 0.10 & 190 & 14.0 & 90 & 45 & 155 & 8 \\
\hline $\mathrm{e}$ & 36.95 & 143.30 & 0.10 & 190 & 14.0 & 90 & 35 & 156 & 5 \\
\hline & & & & & & & & & 0 \\
\hline
\end{tabular}

Fig. 4.2b differed from those of the 2011 Tohoku-oki earthquake (e.g., Fujii and Satake [5], Fig. 4.2a). In addition, the slip amount of type Y section and type A to D sections are empirically average values compared to the exceptionally large value estimated for the 2011 Tohoku-oki earthquake (Fig. 4.2a) compared to the empirical average value of the type Y section in Fig. 4.2b. In order to clarify the influence of high-angle branching faults in this study, two additional models are compared; one is Model2 displayed in Fig. 4.2c consisting of Model1 sub-faults without highangle branching parts (ID; 1, 4, 7, 16, 19 in Table 4.1) and the other is Model3 displayed in Fig. 4.2d replacing high-angle branching parts with extended low-angle sub-faults to the sea bottom with same seismic moment (ID; a-e in 
Table 4.1). The moment magnitude and average slip amount of these three models are calculated as Mw8.9 and $6.6 \mathrm{~m}$ in Model1, Mw8.8 and $6.0 \mathrm{~m}$ in Model2, and Mw8.9 and $5.5 \mathrm{~m}$ in Model3.

\subsection{Tsunami Simulation and Results}

A simulation of tsunami propagation was performed using the TSUNAMI-K software developed by Kozo Keikaku Engineering, Inc., which applies an equation of motion and an equation of continuity including nonlinear long-wave theory with an advective term and a sea-bottom friction term in the Staggered Leapfrog Method. The initial condition of tsunami production was derived from the static tectonic movement calculated from the fault displacement model using the parameters in Table 4.1. The Manning roughness coefficient was assigned the typical value of $0.025\left[\mathrm{~m}^{(-1 / 3)} \mathrm{s}\right]$. A Digital Elevation Model of 50-m grid interval for onshore areas from the Geospatial Information Authority of Japan and a Digital Bathymetry Model of 500-m grid interval for offshore areas from the Hydrographic and Oceanographic Department, Japan Coast Guard were used in the simulation. The grid size for the simulation was assigned as $1350 \mathrm{~m}$, and the duration period for the tsunami simulation was $2 \mathrm{~h}$ with an interval of $1 \mathrm{~s}$ to satisfy the stability condition of the simulation.

Several indices, such as tsunami height, trace height, and run-up height, were adopted from observed tsunami evaluations. However, observational data from onshore and shallow-sea points are directly influenced by local undulation and landforms and were inappropriate for comparison with the simulation results of the Digital Bathymetry Model with its 500-m resolution. Therefore, we compared our simulation results with observed tsunami records from sea-bottom pressure sensors located at points P02 and P06 [7] and tsunami recorder at points TM1 and TM2 [8] in Fig. 4.1a situated off the coast of Iwate to demonstrate the maximum tsunami height. Figure 4.3 shows the comparison of tsunami heights of Model1, Model2, and Model3. The maximum heights obtained from high-angle branching fault simulation (black line) were $2.8 \mathrm{~m}$ at P02, $2.9 \mathrm{~m}$ at P06, $2.7 \mathrm{~m}$ at TM1, and $3.0 \mathrm{~m}$ at TM2. These values are approximately $60 \%$ of the observed maximum height of $5 \mathrm{~m}$ recorded at the 2011 Tokoku-oki earthquake. However, when we used the estimated fault parameters of Fig. 4.2a in our tsunami simulation software to simulate the 2011 Tokoku-oki earthquake, the maximum heights are $0.8 \mathrm{~m}$ smaller with Model1 at TM1 and TM2 though almost same with Model1 at P02 and P06. This means that the sea-bottom deformations of Model1 with high-angle branching fault and average slip amount calculated using the fault dislocation model show almost equivalent potential as the estimated model for the 2011 Tokoku-oki earthquake if we consider the accuracy and limitations of the tsunami simulations. The comparison between three models and observed tsunami height at TM1 and TM2 where these recorders are located at the back of the sections of high-angle branching faults also suggests that earthquakes produced by branching faults with 

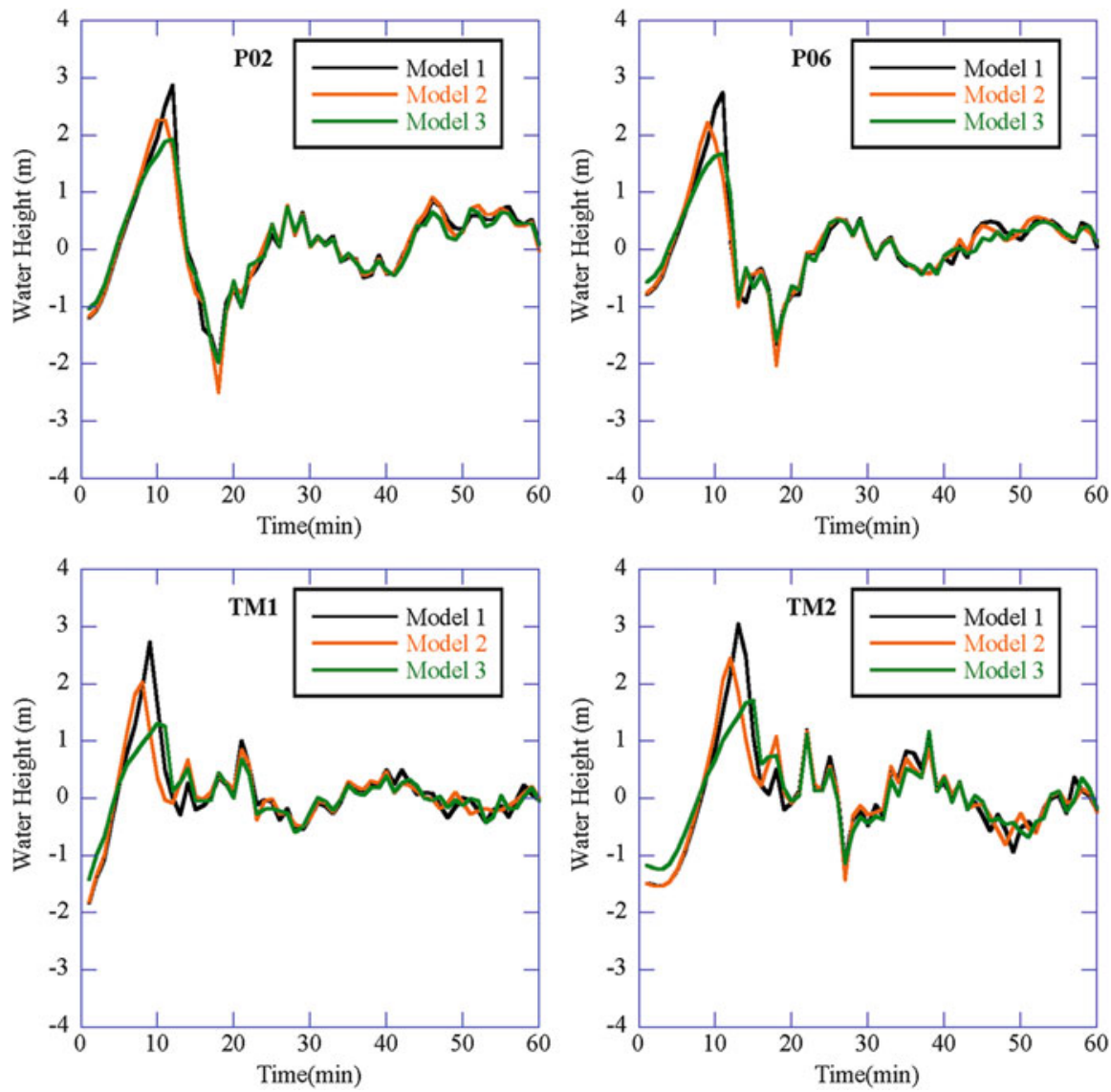

Fig. 4.3 Comparison of simulated tsunami height at points P02, P06, TM1, and TM2 (Fig. 4.1) where the observed data of the 2011 Tohoku-oki earthquake are recorded. Modell, black line; Model2, orange line; Model3, green line

average slip possess a tsunami potential comparable to that produced by the exceptionally large slip of the 2011 Tohoku-oki earthquake at several points along the coast. In other words, the observed severe tsunami of the 2011 Tohokuoki earthquake may not be exceptional for the eastern coast of Tohoku District. The situation is similar along the eastern coast of Japan where faults exist on the continental slope parallel to the trench axis, and the tsunami potential of the highangle branching faults should be considered in the design of disaster prevention measures. 


\subsection{Summary and Conclusion}

The potential of a tsunami produced by a future earthquake due to active faults on the continental slope was identified from the 3D tectonic landform analysis compiled in the Nakata map. Some of these faults display relatively high-angle dipping estimated from seismic profiling records. Thus, the simulated tsunami potential is almost equal to that of the 2011 Tohoku-oki earthquake under limitations of the simulations since faults of high angle with average slip produce effects similar to sea-bottom deformation compared to low-angle faults with exceptionally large slip as in the 2011 Tohoku-oki earthquake.

These active faults on the continental slope are recognized not only along the Japan Trench examined in this study but also the Nankai Trough in the western part of Japan. To evaluate the tsunami potential including both "plate-boundary megathrust" and high-angle branching fault type earthquakes, the Digital Bathymetry Model should be developed further, and the use of combined comprehensive interpretations of geophysical and geomorphological analysis should be promoted.

Acknowledgment The authors thank Prof. Nakata of Hiroshima University for provision of data. This research was supported by Grant-in-Aid for Scientific Research (1940300199).

Open Access This chapter is distributed under the terms of the Creative Commons Attribution Noncommercial License, which permits any noncommercial use, distribution, and reproduction in any medium, provided the original author(s) and source are credited.

\section{References}

1. Nakata T et al (2012) Active faults along Japan Trench and source faults of large earthquakes. http://www.jaee.gr.jp/event/seminar2012/eqsympo/pdf/papers/34.pdf. 19 Dec 2012

2. Okamura Y (2012) Examine the 2011 Tohoku-Oki earthquake from geology (in Japanese). J Earthq 54:1-12

3. Kato Y (2000) Mega-submarine slide and geological structure off Fukusima. Abstracts Japan Earth and Planetary Science Joint Meeting: Sj-P004

4. Ueta K, Tani K (1999) Deformation of Quaternary deposits and ground surface caused by bedrock fault movements (Part 2)-normal and reverse fault model tests- (in Japanese). Rep Cent Res Inst Electr Power Ind U98048:1-40

5. Fujii Y, Satake K (2011) Tsunami source models of the 2011/03/11 Tohoku-oki earthquake (preliminary result). http://iisee.kenken.go.jp/staff/fujii/OffTohokuPacific2011/tsunami_ja.html

6. HERP (2008) Recipe for predicting strong ground motion from subduction earthquake (in Japanese). http://www.jishin.go.jp/main/kyoshindo/05dec_miyagi/recipe.pdf

7. Saito $\mathrm{T}$ et al (2011) Tsunami source of the 2011 Tohoku-oki earthquake, Japan: inversion analysis based on dispersive tsunami simulations. Geophys Res Lett 38. doi:10.1029/ 2011GL049089

8. Maeda T et al (2011) Significant tsunami observed at the ocean-bottom pressure gauges at 2011 Off the Pacific Coast of Tohoku Earthquake. Earth Planets Space. doi:10.5047/eps.2011.06.005 